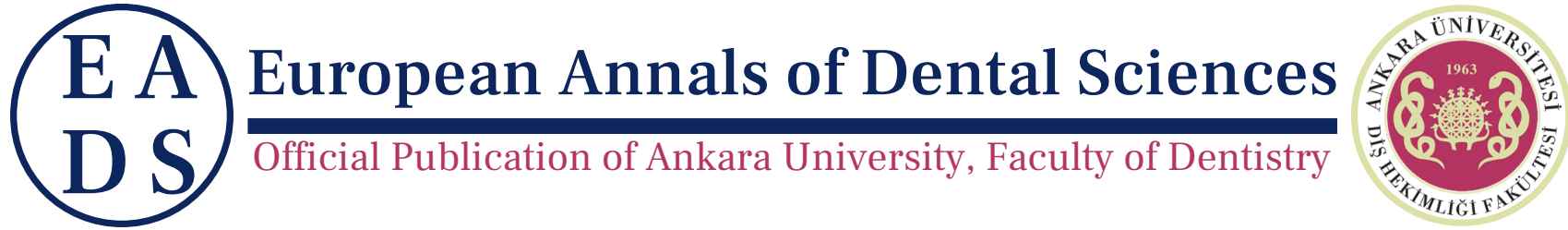

EADS, 2021, $48(2), 46-51$

\title{
Investigation of Water Absorption and Color Change of Indirect Composite Resins
}

\author{
Nur İskender $\odot$, Bilge Ersöz $\odot$ 2,*, Numan Aydın $\odot 2$, Serpil \\ Karaoğlanoğlu $\odot 2$ and Elif Aybala Oktay $\odot 2$
}

${ }^{1}$ Cankayadent Oral and Dental Health Clinic, Ankara, Turkey and ${ }^{2}$ University of Health Sciences, Gulhane Faculty of Dentistry, Department of Restorative Dental Treatment, Ankara, Turkey

*Corresponding Author; bilgecaliskan9@gmail.com

\begin{abstract}
Purpose: Since conventional composite resins have some disadvantages such as polymerization shrinkage and secondary caries formation, indirect restorations are preferred in cases where tooth tissue loss is high. The aim of this study is to examine the water absorption and color change of indirect composite resins in different beverages.

Materials \& Methods: In the study, 40 specimens $(10 \times 2 \mathrm{~mm})$ were arranged from each composite using three indirect (Signum Composite, Signum Ceramis and Gradia Plus) and one conventional (GrandioSO) composite resin. After the specimens were polished, they were used for water absorption and color change test. The water absorption test was performed through keeping them in water for 7 days as specified in ISO 4049:2009. Samples were kept in coffee, tea and distilled water for 7 days in order to examine color differences. The water absorption and color change values of the composite resins at the end of the 7th day were appraised using one-way analysis of variance (ANOVA) and Tukey's test $(\mathrm{p}<0.05)$.

Results: While there was no statistically considerable difference between the water absorption data of the indirect and traditional composite resin materials we used in the study ( $p>0.05)$. When the color changes of resin-containing composites in water, coffee and tea were examined, traditional composite resin (GrandioSO) showed statistically less color change than indirect composites in water, coffee and tea $(\mathrm{p}<0.05)$.

Conclusion: Although indirect composite resins showed similar water absorption with conventional composite, they showed more color change than conventional composite. The highest color change in indirect composites was seen in coffee solution. Particle size of the indirect composites do not affect water absorption, but the decrease in particle size of composites shows less color change.
\end{abstract}

Key words: color stability; indirect composite resins; water absorption

\section{Introduction}

In recent years, esthetic restoration applications in the posterior regions have become popular with growing demand for higher esthetics in dental treatments. Numerious materials and techniques have been introduced in this field. Light-cured direct composites are preferred in posterior cases where tissue loss is less. ${ }^{1}$ Because they have some disadvantages such as polymerization shrinkage, difficulty in adaptation to cavity walls, microleakage, development of secondary caries, indirect restorations are preferred in cases where excess tissue is lost. ${ }^{2}$ Indirect composite and ceramic based materials are used in the production of indirect restorations. ${ }^{2,3}$
The indirect composites were first introduced in $1982^{4}$ and provided the ease of fabrication, better establishment of anatomical form, marginal adaptation, interproximal contact and contour formations and good wear resistance and a reduced polymerization shrinkage compared to direct composites. ${ }^{5} \mathrm{Be}-$ sides, indirect composites do not carry the disadvantages of inlay ceramics such as abrasion of opposing teeth, absorption of a small part of the masticatory forces due to their high elasticity modulus, ${ }^{6}$ being more fragile and not being able to be repaired safely in the mouth, and also are cheaper than inlay ceramic alternatives. ${ }^{7}$

However the first produced indirect composites displayed low mechanical features because of a low percent of inorganic 
filler particles and a high percent of displayed resin. ${ }^{8}$ By 1990 s several new indirect composite resins came into the market that including higher percentage of inorganic fillers and exhibited better mechanical properties ${ }^{9}$ and since than indirect laboratuary composite systems are continuously featured with newer formulations of resins and fillers and different curing mechanisms. ${ }^{10}$ Although many improvements have been made in the composite materials, water sorption and discoloration of the composite resins still appear to be significant problems and are thought to affect the clinic succsess of the dental restorations. ${ }^{11,12}$

Water sorption has some negative effects such as reduction in wear resistance ${ }^{13,14}$ and strenght, ${ }^{15-17}$ release of monomers which do not react, and hydrolytic breakage of bonds at the resin-filler interface ${ }^{18}$ of restorations. It is also accepted that water sorption affects the volume of resin materials by hygroscopic expansion, ${ }^{19}$ which can cause microcracks or even cracks in restored teeth. ${ }^{20}$

Color stabilitiy of the composite resins is crucial in determining restoration sucsess. ${ }^{21}$ In composite resins, discoloration may result from internal factors like chemical dissociaton of the resin matrix and/or the resin matrix filler and external factors like surface sorption due to colored foodsbeverages and/or smoking. ${ }^{22-24}$ Although some studies have reported that indirect composite resins show sufficient color stability, ${ }^{11,25,26}$ some other studies have reported clinically unacceptable color changes. ${ }^{27,28}$

It can be concluded that there are conflicting results in the literature about discoloration of indirect composites. In addition, although there are several researchs about the water sorption charactersitcs of dental composites, actual number of studies examining these properties of indirect composites and their relationship with discoloration is limited.

Since indirect composites are polymerized in the laboratory environment, it is thought that they will absorb less water and be more resistant to extrinsic stains than conventional composite resins. The aim of this study is to examine the water absorption and discoloration of indirect composites in different solutions.

\section{Materials and Methods}

\section{Preparation of samples}

Signum Composite (Kulzer, Germany), Signum Ceramis (Kulzer, Germany), Gradia Plus (GC, Japan) indirect composite and GrandioSo (Voco, Germany) conventional composites were used in the study (Table 1). Composite specimens were prepared using a silicone mold with a diameter of $8 \mathrm{~mm}$ and a height of $2 \mathrm{~mm}$. A total of 160 samples were prepared, 40 from each composite. Prepared samples were used for water absorption $(n=8)$ and color change $(n=8)$ experiments. In the preparation of the specimens, composite resins were placed in the cavity on the silicone mold with a mouth spatula and a 1 mm glass (coverslip) was placed on the mylar strip. Conventional composite resins were polymerized for 20 seconds using a LED light device (DTE Lux-E, Germany). Labolight DUO (GC, Germany) was used for the polymerization of indirect composite resins and indirect composite resins were polymerized for 3 minutes. The finishing and polishing processes of the composite resin specimens were carried out under water cooling with the diamond finishing and polishing system (Clearfil Twist Dia, Kuraray) at $10,000 \mathrm{rpm}$ for 20 seconds.

\section{Water absorption}

Water absorption and solubility values of specimens were determined according to ISO 4049:2009. The arranged specimens were embedded in a desiccator including anhydrous calcium chloride and held on $(37 \pm 1){ }^{\circ} \mathrm{C}$ for $22 \mathrm{~h}$ and then in a similar desiccator at $(23 \pm 2)^{\circ} \mathrm{C}$ for $2 \mathrm{~h}$. The specimens taken from the desiccator were weighed (Mettler AT201, Switzerland) until they came to constant weight (M1). After the measurement, the specimens were kept in the incubator (Heraeus D-6450 Hanau) in $10 \mathrm{~mL}$ of distille water (Veolia, England) at $(37 \pm 1)^{\circ} \mathrm{C}$ for 7 days and then they were taken from the water and the moisture on their surfaces was removed with blotter paper and they were weighed again (M2).

The weighed specimens were embedded in a desiccator containing anhydrous calcium chloride and at $(37 \pm 1){ }^{\circ} \mathrm{C}$ for $22 \mathrm{~h}$, then in the desiccator at $(23 \pm 2){ }^{\circ} \mathrm{C}$ for $2 \mathrm{~h}$. The specimens taken from the desiccator were weighted (within $15 \mathrm{sec}$ ) with Mettler AT201, Switzerland (M3).

Water absorption $=M_{2}-M_{3} / \mathrm{V}$

- M2 = Weight of specimens weighed after placing in water $(\mu \mathrm{g} / \mathrm{mm} 3)$

- M3 = Weight of specimens weighed after drying ( $\mu \mathrm{g} / \mathrm{mm} 3)$

- $\mathrm{V}=$ Volume of specimens $(\mathrm{mm} 3)$

\section{Color change}

After finishing and polishing processes, composite specimens which would be used for color change were kept in incubator (FN 500, Nüve, Turkey) for $24 \mathrm{~h}$ in distilled water at $37^{\circ} \mathrm{C}$. After the composite specimens were immersed in distilled water for $24 \mathrm{~h}$, the initial color of the specimens belonging to each group was measured using a spectrophotometer device (Vita Easyshade; VITA Zahnfabrik, Germany). After determining the initial color of the specimens, they were kept in coffee (Nescafe Classic, Turkey) in the incubator (FN 500, Nüve, Turkey) for 7 days at $37^{\circ} \mathrm{C}$. Color measurements of the specimens at the end of 7 days were made and $\mathrm{L}^{*}, \mathrm{a}^{*}$ and $\mathrm{b}^{*}$ values were recorded. The coffee solution was prepared by dissolving $2 \mathrm{~g}$ of coffee powder in $200 \mathrm{ml}$ of boiled distilled water. Tea solution (Lipton, Turkey) was prepared by dissolving $20 \mathrm{~g}$ pack in $200 \mathrm{ml}$ of boiled distilled water. Distilled water was used as the control group. The prepared coffee and tea solution added onto the specimens at $37{ }^{\circ} \mathrm{C}$. It was also replaced with a new coffee solution every $24 \mathrm{~h}$. In the calculation of color changes in composites, the formula $\left(\Delta \mathrm{E}_{00}\right)$ in the formula CIEDE2000 was used over the parameters $L^{*}, a^{*}$ and $b^{*}$.

$$
\Delta E_{00}=\sqrt{\left(\frac{\Delta L^{\prime}}{K_{L} S_{L}}\right)^{2}+\left(\frac{\Delta C^{\prime}}{K_{C} S_{C}}\right)^{2}+\left(\frac{\Delta H^{\prime}}{K_{H} S_{H}}\right)^{2}+R_{T}\left(\frac{\Delta C^{\prime}}{K_{C} S_{C}}\right)\left(\frac{\Delta H^{\prime}}{K_{H} S_{H}}\right)}
$$

\section{Statistical analysis}

Statistical analysis was realized using SPSS 22.0 Statistical Program (SPSS Inc., Chicago, IL, USA). The water absorption and color change values of the composite resins at the end of the 7th day were evaluated using (ANOVA) and Tukey's test. The statistical significance level was considered as $\mathrm{p}<0.05$.

\section{Results}

As a result of this study in which was examining the water absorption and color change of resin-containing restorative materials, there was no statistically remarkable difference 
Table 1. Restorative materials containing resin used in the study

\begin{tabular}{|c|c|c|c|c|c|c|}
\hline Composites & Type & $\begin{array}{l}\text { Matrix } \\
\text { type }\end{array}$ & Filler type & Filler ratio & $\begin{array}{l}\text { Particle } \\
\text { size }\end{array}$ & $\begin{array}{c}\text { Lot } \\
\text { number }\end{array}$ \\
\hline Signum composite (Kulzer, Germany) & Indirect Composite & $\begin{array}{l}\text { TEGDMA, } \\
\text { dodecan- } \\
\text { di- } \\
\text { oldimethacry- } \\
\quad \text { late }\end{array}$ & Prepolimers & $\% 74$ & $\begin{array}{l}1 \mu \mathrm{m} \\
\text { (micro } \\
\text { size) }\end{array}$ & K010520 \\
\hline Signum ceramis (Kulzer, Germany) & Indirect Composite & $\begin{array}{l}\text { BAGDE- } \\
\text { DA } \\
\text { TEGDMA }\end{array}$ & $\begin{array}{l}\text { Dental } \\
\text { glass }\end{array}$ & $\% 73$ & $\begin{array}{c}0.6-1 \mu \mathrm{m} \\
\text { (micro } \\
\text { size) }\end{array}$ & K010304 \\
\hline Gradia Plus (GC Europe, Germany) & Indirect Composite & UDMA,EDMA & - & $\% 71$ & $\begin{array}{c}300 \mathrm{~nm} \\
\text { (ultrafine) }\end{array}$ & $190917 \mathrm{~A}$ \\
\hline GrandioSO (Voco, Germany) & Conventional Composite & $\begin{array}{l}\text { TEGDMA, } \\
\text { Bis-GMA, } \\
\text { Bis-EMA }\end{array}$ & $\begin{array}{c}\text { Baryum } \\
\text { glass }\end{array}$ & $\% 89$ & $\begin{array}{l}1 \mu \mathrm{m} \text { and } \\
20-40 \mathrm{~nm}\end{array}$ & 2005147 \\
\hline
\end{tabular}

Table 2. Examination of water absorption and color change $\left(\Delta \mathrm{E}_{00}\right)$ of resin-containing restorative materials at the end of the 7th day

\begin{tabular}{lrrrr}
\hline Composites & Water Absorption & Color Change Water & Color Change Coffee & Color Change Tea \\
\hline Signum ceramis & $4.38 \pm 1.6$ & $1.41 \pm 0.4^{\mathrm{a}}$ & $8.98 \pm 1.6^{\mathrm{a}}$ & $3.92 \pm 0.7^{\mathrm{a}}$ \\
Signum composite & $4.48 \pm 1.4$ & $1.66 \pm 0.2^{\mathrm{a}}$ & $11.20 \pm 1.6^{\mathrm{b}}$ & $5.24 \pm 0.9^{\mathrm{b}}$ \\
Gradia Plus & $3.88 \pm 1.7$ & $1.47 \pm 0.4^{\mathrm{a}}$ & $7.17 \pm 1.2^{\mathrm{a}}$ & $3.16 \pm 0.9^{\mathrm{a}}$ \\
GrandioSO & $4.08 \pm 1.2$ & $0,94 \pm 0.3^{\mathrm{b}}$ & $3.46 \pm 1.1^{\mathrm{c}}$ & $2.11 \pm 0.5^{\mathrm{c}}$ \\
$\mathrm{p}$ & 0.804 & 0.001 & 0.000 & 0.000 \\
\hline
\end{tabular}

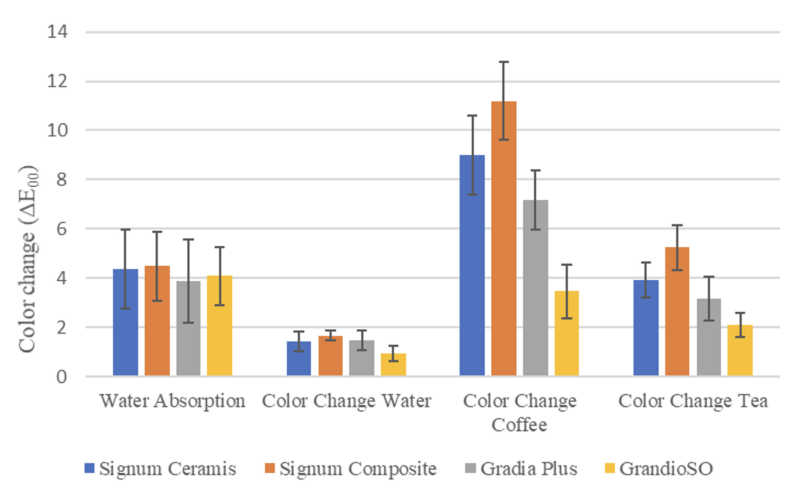

Figure 1. Examination of color change $\left(\Delta \mathrm{E}_{00}\right)$ of resin-containing restorative materials at the end of the 7 th day

between the water absorption data of the materials ( $p>0.05)$, while there was a statistically remarkable difference between the color changes $(\mathrm{p}<0.05)$ (Figure 1).

Among indirect composite resins, the indirect composite Gradia Plus was the lowest in water absorption, while the indirect composite Signum composite was highest. Although traditional composite resin (GrandioSo) showed less water absorption than indirect composite resins (Signum Ceramis and Signum Composite), it showed more water absorption than the other indirect composite resin Gradia Plus.

When the color changes of resin-containing materials in water, coffee and tea were examined, conventional composite resin (GrandioSO) showed statistically less color change than indirect composites $(\mathrm{p}<0.05)$. No statistically remarkable difference was found between the color changes of indirect composite resins in water $(\mathrm{p}>0.05)$. While indirect composite (Signum Composite) with composite content showed the highest color change in tea and coffee, no statistically remarkable color difference was observed among other indirect composites (Gradia Plus and Signum Ceramis) (Table 2).

\section{Discussion}

Indirect composite resins are shown as an alternative to direct composite resin and ceramic inlays in restorations of posterior teeth. Although it is suggested that they have superior physical and mechanical properties compared to composite resins, ${ }^{28,29}$ studies have reported that these materials also have water absorption properties and can change color. ${ }^{27,28}$

The standard limit for water absorption of restorative materials is reported as $40 \mu \mathrm{g} / \mathrm{mm} 3 .{ }^{11}$ It was determined that the water absorption values of all resin materials evaluated in this study after 1 week of water storage ranged from 3.88 to 4.48 $\mu \mathrm{g} / \mathrm{mm} 3$ and were below this limit. Water absorption into the polymeric material is a phenomenon controlled by diffusion and is explained by two different theories. The first of these is the free volume theory and expresses the solvent absorption through the gaps in the polymer. ${ }^{30}$

The high level of polymerization of the composite resin reduces the number of unreacted carbon-carbon double bonds, resulting in less water absorption of the material. It is suggested that polymerization will be at a higher rate in indirect composites. ${ }^{9}$ However, there was no statistical difference in water absorption between indirect and direct composites examined in this study. When indirect composites are compared with direct composites, it was reported that indirect composites show higher water absorption. ${ }^{10}$ However, the water absorption values determined by the researcher at the end of 1 week range between 13.83 and 24.06 and are above the values of this study. It was stated that water absorption is a weak predictor in showing the degree of conversion. ${ }^{31}$ Therefore, it is suggested that the second theory in water absorption, the interaction theory, is of greater importance. ${ }^{32}$ According to this, water is bounded to some ionic groups in the polymer structure, depending on the affinity of these groups to water (whether they are hydrophilic or hydrophobic). 33 Bisphenol A glycidyl methacrylate (Bis-GMA), urethane dimethacrylate (UDMA), and triethylene glycol dimethacrylate (TEGDMA) methacrylic monomers are the main components of resinbased filler materials and water absorption from highest to lowest is ordered as TEGDMA > Bis-GMA > UDMA > Bis-EMA. 34 
In this study, the indirect composite Gradia Plus showed the lowest water absorption. This composite resin is the only material with UDMA among all the materials evaluated in this study, and the fact that UDMA is a hydrophobic monomer may have played a role in the lower water absorption of Gradia Plus. When the water absorption of different composite resins was evaluated, the lower water absorption of Durafill resin attributed to its content of UDMA monomer. ${ }^{35}$ On the other hand, the direct composite GrandioSO was the second least water absorbent resin material, and it is thought that containing the most hydrophobic monomer Bis-EMA may have been effective in this result. Signum composite, on the other hand, contained TEGDMA, which showed the highest water absorption. However, TEGDMA is also one of the monomers in the structure of GrandioSO and Signum Ceramis and it should be taken into account that other factors may also be effective in explaining the slightly high-water absorption of the Signum composite.

Studies show that there is a negative correlation between the water absorption of composite resins and the amount of filler. ${ }^{11,36}$ As the weight \% of the fillers increases, water absorption decreases together with the polymeric matrix. ${ }^{36}$ GrandioSO, the only direct a larger surface area composite in this study, has a very high filler rate of $89 \%$, and this filler ratio may be one of the important reasons why there is no statistical difference between it and indirect composites in terms of water absorption.

Particle amount as well as the particle size is reported to play an important role in a larger surface area water absorption. ${ }^{37}$ Micro filler particles with larger surface areas have higher rates of water absorption. While particle sizes of Signum ceramics and Signum composites vary between 0.6-1 $\mu$, Gradia Plus's ultrafine particles with the size of $300 \mathrm{~nm}$ may be another factor that played a role in lower water absorption compared to these two materials.

One of the most significant esthetic characteristics in dentistry is color, and the discoloration of restorative materials is one of the main causes for restoration renewal. In this work, the color changes in composites were calculated using the CIEDE2000 formula $\left(\Delta \mathrm{E}_{00}\right)$. Color is one of the most important esthetic parameters in dentistry and the coloring of restorative materials is one of the most important reasons for restoration renewal. In this study, the formula $(\triangle \mathrm{E} 00)$ in the CIEDE2000 formula was used to calculate the color changes in composites. In studies examining the color stability of resin composites, it is seen that the CIELab difference formula is mostly used, and the number of studies done with the CIEDE2000 formula is more limited. In addition, it is seen that there have been some changes in the perceptibility and acceptability thresholds of both CIEDE2000 and CIELab formulas over the years. It was reported that perceptible match values for ${ }^{38} \Delta \mathrm{E}$ values were 3.3, and many studies were evaluated the clinical suitability of the examined materials based on these values. Again, for $\Delta \mathrm{E}_{00}$, the acceptable match value is reported as 2.25 . However, in another study ${ }^{39} \Delta \mathrm{E}_{00}$ acceptable match values were determined as $0.8<1.8$ and values between $1.8<3.6$ were expressed as moderately unacceptable, $3.6 \leq 5.4$ as clearly unacceptable, and values above 5.4 as extremely unacceptable. According to this more current value, it was determined that the in-water color changes (0.94-1.66) of all resin-containing materials included in this study was in the acceptable match range at the end of 1 week. However, as a result of immersion periods of 1 week in both tea and coffee, all resin-containing materials failed to stay below acceptable limits. Despite the fact that much longer waiting times were applied in colorant solutions, in this study, it was found that acceptable values were exceeded even within a week. These values are compatible with the color change values determined in a study examining ${ }^{40}$ the color changes of indirect lab and CAD-CAM composites at the end of
1 week. Also, the color stability of some indirect composites by thermal cycle was evaluated and stated that the obtained color change values above clinically acceptable values were found in all composite resins. ${ }^{41}$

In this study, direct composite resin (Grandioso) showed statistically less color change than indirect composites. These results were surprising as indirect composites were generally thought to have better color stability due to their higher conversion degree. Also, no difference was reported between the color stability of indirect and direct composites. ${ }^{26}$ These results suggest that other factors such as filler types, matrix types, filler ratios, particle size of composites may have a more in study evaluating the color stability and surface roughness of indirect composites that the composite resin with the lowest filler showed the highest color change. Grandioso had the highest filler content among the materials tested, and this rate of filler may be one of the important factors in the low color change.

On the other hand, it is seen that the indirect composites in this study have close filler ratios. However, Signum Composite showed statistically significantly higher color change in tea and coffee than other indirect composites. Signum composite was also the resin that showed the highest water absorption in this study, this result can be considered consistent with studies reporting a significant relationship between water absorption and $\Delta \mathrm{E} .{ }^{42}$ In addition, the fact that the color change of this composite in water is not different from other indirect composites suggests that it is more affected by the structure of tea and coffee. Tea has a rich structure of tannin and tannin has a property that increases the ability of chromogens to adhere to the surface of materials. Coffee contains high amounts of chromogen. Both of beverages that contain color pigment causes discoloration on the surface of the materials. Fillers of Signum Composite are composed of prepolymerized composites, while fillers (dental glass) of Signum Ceramis may be more resistant to color pigments.

\section{Conclusion}

Although indirect composite resins showed similar water absorption with conventional composite after 7 days, they showed more color change than conventional composite. The most color change in indirect composites was seen in coffee. Therefore, it will be useful to evaluate the color change of indirect composite resins with clinical studies.

\section{Author Contributions}

N.I., B.E. and N.A. participated in designing the study. S.K. and N.A. participated in generating the data for the study. N.I., N.A. and B.E. participated in gathering the data for the study. N.A. participated in the analysis of the data. N.I. and B.E. wrote the majority of the original draft of the paper. N.I., S.K., N.A. and E.A.O. participated in writing the paper.

\section{Conflict of Interest}

The authors declare no competing interests.

\section{Authors' ORCID(s)}

N.I. $\quad 0000-0001-6522-5284$

B.E. $0000-0003-0769-0457$

N.A. $0000-0001-8628-4507$

S.K. $\quad 0000-0003-0601-8028$

E.A.O. 0000-0003-1668-0592 


\section{References}

1. Tjan AH, Bergh BH, Lidner C. Effect of various incremental techniques on the marginal adaptation of class II composite resin restorations. J Prosthet Dent. 1992;67(1):62-6. doi:10.1016/0022-3913(92)90051-b.

2. van Dijken JW, Höglund-Aberg C, Olofsson AL. Fired ceramic inlays: a 6-year follow up. J Dent. 1998;26(3):21925. doi:10.1016/s0300-5712(97)00005-5.

3. Fron Chabouis H, Smail Faugeron V, Attal JP. Clinical efficacy of composite versus ceramic inlays and onlays: a systematic review. Dent Mater. 2013;29(12):1209-18. doi:10.1016/j.dental.2013.09.009.

4. Mormann WH. [Composite inlays: a research model with practice potential?]. Quintessenz. 1982;33(10):1891-901.

5. Burgoyne AR, Nicholls JI, Brudvik JS. In vitro twobody wear of inlay-onlay composite resin restoratives. J Prosthet Dent. 1991;65(2):206-14. doi:10.1016/00223913(91)90163-q.

6. Coldea A, Swain MV, Thiel N. Mechanical properties of polymer-infiltrated-ceramic-network materials. Dent Mater. 2013;29(4):419-26. doi:10.1016/j.dental.2013.01.002.

7. Burke EJ, Qualtrough AJ. Aesthetic inlays: composite or ceramic? Br Dent J. 1994;176(2):53-60. doi:10.1038/sj.bdj.4808363.

8. Touati B. The evolution of aesthetic restorative materials for inlays and onlays: a review. Pract Periodontics Aesthet Dent. 1996;8(7):657-66; quiz 668.

9. Touati B, Aidan N. Second generation laboratory composite resins for indirect restorations. J Esthet Dent. 1997;9(3):108-18. doi:10.1111/j.1708-8240.1997.tbo0928.x.

10. Jain VV. Evaluation of second generation indirect composite resins [Thesis]; 2008.

11. Janda R, Roulet JF, Latta M, Rüttermann S. Water sorption and solubility of contemporary resin-based filling materials. J Biomed Mater Res B Appl Biomater. 2007;82(2):54551. doi:10.1002/jbm.b.30760.

12. Seyidaliyeva A, Rues S, Evagorou Z, Hassel AJ, Rammelsberg P, Zenthöfer A. Color stability of polymerinfiltrated-ceramics compared with lithium disilicate ceramics and composite. J Esthet Restor Dent. 2020;32(1):4350. doi:10.1111/jerd.12525.

13. Beatty MW, Swartz ML, Moore BK, Phillips RW, Roberts TA. Effect of microfiller fraction and silane treatment on resin composite properties. J Biomed Mater Res. 1998;40(1):1223. doi:10.1002/(sici)1097-4636(199804)40:1<12::aidjbm2>3.0.co;2-u.

14. Göhring TN, Besek MJ, Schmidlin PR. Attritional wear and abrasive surface alterations of composite resin materials in vitro. J Dent. 2002;30(2-3):119-27. doi:10.1016/s03005712(02)00007-6.

15. Mortier E, Gerdolle DA, Jacquot B, Panighi MM. Importance of water sorption and solubility studies for couple bonding agent-resin-based filling material. Oper Dent. 2004;29(6):669-76.

16. Musanje L, Shu M, Darvell BW. Water sorption and mechanical behaviour of cosmetic direct restorative materials in artificial saliva. Dent Mater. 2001;17(5):394-401. doi:10.1016/s0109-5641(00)00097-x.

17. Sideridou I, Tserki V, Papanastasiou G. Study of water sorption, solubility and modulus of elasticity of lightcured dimethacrylate-based dental resins. Biomaterials. 2003;24(4):655-65. doi:10.1016/s0142-9612(02)00380-0.

18. Yiu CK, King NM, Pashley DH, Suh BI, Car- valho RM, Carrilho MR, et al. Effect of resin hydrophilicity and water storage on resin strength. Biomaterials. 2004;25(26):5789-96. doi:10.1016/j.biomaterials.2004.01.026.

19. Alrahlah A, Silikas N, Watts DC. Hygroscopic expansion kinetics of dental resin-composites. Dent Mater. 2014;30(2):143-8. doi:10.1016/j.dental.2013.10.010.

20. Rüttermann S, Krüger $S$, Raab WH, Janda R. Polymerization shrinkage and hygroscopic expansion of contemporary posterior resin-based filling materialsa comparative study. J Dent. 2007;35(10):806-13. doi:10.1016/j.jdent.2007.07.014.

21. Nakazawa M. Color stability of indirect composite materials polymerized with different polymerization systems. J Oral Sci. 2009;51(2):267-73. doi:10.2334/josnusd.51.267.

22. Guler AU, Kurt S, Kulunk T. Effects of various finishing procedures on the staining of provisional restorative materials. J Prosthet Dent. 2005;93(5):453-8. doi:10.1016/j.prosdent.2005.02.001.

23. Topcu FT, Sahinkesen G, Yamanel K, Erdemir U, Oktay EA, Ersahan S. Influence of different drinks on the colour stability of dental resin composites. Eur J Dent. 2009;3(1):506.

24. Villalta P, Lu H, Okte Z, Garcia-Godoy F, Powers JM. Effects of staining and bleaching on color change of dental composite resins. J Prosthet Dent. 2006;95(2):137-42. doi:10.1016/j.prosdent.2005.11.019.

25. Kim SH, Lee YK. Changes in color and color coordinates of an indirect resin composite during curing cycle. J Dent. 2008;36(5):337-42. doi:10.1016/j.jdent.2008.01.013.

26. Lee YK, Yu B, Lim HN, Lim JI. Difference in the color stability of direct and indirect resin composites. J Appl Oral Sci. 2011;19(2):154-60. doi:10.1590/s167877572011000200012.

27. Rosentritt M, Esch J, Behr M, Leibrock A, Handel G. In vivo color stability of resin composite veneers and acrylic resin teeth in removable partial dentures. Quintessence Int. 1998;29(8):517-22.

28. Zanin FR, Garcia Lda F, Casemiro LA, Pires-de Souza Fde C. Effect ofartificial accelerated aging on color stability and surface roughness of indirect composites. Eur J Prosthodont Restor Dent. 2008;16(1):10-4.

29. Mainjot AK, Dupont NM, Oudkerk JC, Dewael TY, Sadoun MJ. From Artisanal to CAD-CAM Blocks: State of the Art of Indirect Composites. J Dent Res. 2016;95(5):487-95. doi:10.1177/0022034516634286.

30. Wei YJ, Silikas N, Zhang ZT, Watts DC. Diffusion and concurrent solubility of self-adhering and new resin-matrix composites during water sorption/desorption cycles. Dent Mater. 2011;27(2):197-205. doi:10.1016/j.dental.2010.10.014.

31. Rueggeberg FA, Craig RG. Correlation of parameters used to estimate monomer conversion in a light-cured composite. J Dent Res. 1988;67(6):932-7. doi:10.1177/00220345880670060801.

32. Ortengren $U$, Wellendorf $H$, Karlsson S, Ruyter IE. Water sorption and solubility of dental composites and identification of monomers released in an aqueous environment. J Oral Rehabil. 2001;28(12):1106-15. doi:10.1046/j.13652842.2001.00802.x.

33. Chaves LP, Graciano FMO, Júnior OB, do Vale Pedreira APR, Manso AP, Wang L. Water interaction with dental luting cements by means of sorption and solubility. Brazilian Dental Science. 2012;15(4):29-35.

34. Venz S, Dickens B. NIR-spectroscopic investigation of water sorption characteristics of dental resins and composites. J Biomed Mater Res. 1991;25(10):1231-48. doi:10.1002/jbm.820251005. 
35. Rahim TN, Mohamad D, Md Akil H, Ab Rahman I. Water sorption characteristics of restorative dental composites immersed in acidic drinks. Dent Mater. 2012;28(6):e6370. doi:10.1016/j.dental.2012.03.011.

36. Alshali RZ, Salim NA, Satterthwaite JD, Silikas N. Longterm sorption and solubility of bulk-fill and conventional resin-composites in water and artificial saliva. J Dent. 2015;43(12):1511-8. doi:10.1016/j.jdent.2015.10.001.

37. Oysaed H, Ruyter IE. Water sorption and filler characteristics of composites for use in posterior teeth. J Dent Res. 1986;65(11):1315-8. doi:10.1177/00220345860650110601.

38. Ruyter IE, Nilner K, Moller B. Color stability of dental composite resin materials for crown and bridge veneers. Dent Mater. 1987;3(5):246-51. doi:10.1016/s01095641(87)80081-7.

39. Paravina RD, Pérez MM, Ghinea R. Acceptability and per- ceptibility thresholds in dentistry: A comprehensive review of clinical and research applications. J Esthet Restor Dent. 2019;31(2):103-112. doi:10.1111/jerd.12465.

40. Arocha MA, Basilio J, Llopis J, Di Bella E, Roig M, Ardu $\mathrm{S}$, et al. Colour stainability of indirect CAD-CAM processed composites vs. conventionally laboratory processed composites after immersion in staining solutions. J Dent. 2014;42(7):831-8. doi:10.1016/j.jdent.2014.04.002.

41. Bicer AZY, Karakıs D, Dogan A. Termal siklusun indirekt kompozit rezin materyallerinin renk stabilitesi üzerine etkisi. Acta Odontologica Turcica. 2014;31(1):13-17.

42. Shiozawa $M$, Takahashi $H$, Asakawa $Y$, Iwasaki N. Color stability of adhesive resin cements after immersion in coffee. Clin Oral Investig. 2015;19(2):309-17. doi:10.1007/s00784-014-1272-8. 